DOSSIÊ: CORPOS, TRAJETÓRIAS E VALORES: PERSPECTIVAS DE GÊNERO, FAMÍLIAS E REPRODUÇÃO SOCIAL EM CONTEXTOS AFRICANOS

\title{
"Este país é cheio de apartheid", diálogos com mulheres sul-africanas na província de KwaZulu-Natal*
}

\author{
Maíra Cavalcanti Vale**
}

\section{Resumo}

Esse artigo busca traçar paralelos entre o caminho pelo qual a ideologia africâner, apoiada indiretamente pelos sul-africanos de origem inglesa, ganhou forças no cenário político sul-africano configurando-se de um sistema legal de segregação para o racismo instituído do apartheid - e causou influências no cotidiano das pessoas não brancas daquele país, afetando diretamente elementos cosmológicos que mobilizam o seu dia-a-dia. A partir da violência que promoveu diversas remoções na zona rural, os efeitos do apartheid causaram pendências com os ancestrais que as pessoas de origem zulu e moradoras das regióes afetadas têm de lidar até os dias atuais, em um movimento que busca acertar as contas com o passado.

Palavras-chave: Mulheres, África do Sul, Apartheid, Ancestralidade, Terra.

\footnotetext{
* Recebido para publicação em 12 de maio de 2015, aceito em 20 de agosto de 2015. Uma versão anterior deste artigo foi apresentada no GT Estudos Africanos no Brasil: perspectivas, diálogos e desafios na $28^{\mathrm{a}}$ Reunião Brasileira de Antropologia de 2012; ele também é fruto da minha dissertação de mestrado, Prosa que tece a vida, estórias de mulheres em KwaZulu-Natal, África do Sul (Vale, 2013).

** Doutoranda pelo Programa de Pós-graduação em Antropologia Social, Unicamp, Campinas, SP, Brasil. vale.maira@gmail.com 
Intertwining Words, Talks with South African Women in the KwazuluNatal Province

\begin{abstract}
This article is an attempt to draw the parallels between the way in which the Afrikaner ideology, supported by the British group, gained strength in the South African political scene - from the legal system of segregation to the racism instituted system of apartheidand caused direct influences on daily life of the non-white SouthAfricans, directly affecting cosmological elements that mobilize their day-to-day. From the violence that has organized various removals in the countryside, the effects of the apartheid caused disagreements with the ancestors that people have to deal to the present day, in a movement that seeks to come to terms with the past.
\end{abstract}

Key Words: Women, South Africa, Apartheid, Ancestry, Land. 
Apartheid (palavra do Afrikaans para apart-ação) foi um sistema de segregação legalmente forçada pela minoria branca no poder da África do Sul de 1948 a 1994. O Population Registration Act [Ato de registro populacional] (1950) ${ }^{1}$ classificava todos os cidadãos por grupos raciais. Pessoas de diferentes raças foram proibidas de entrar na mesma loja, atender à mesma escola ou viver debaixo do mesmo teto (Skin, 2008). ${ }^{2}$

É assim que começa o filme sul-africano Skin: palavras por cima de uma paisagem - mato seco e montanhas. Elas são fundamentais para se entender o filme que é baseado numa história real. Para acompanhar o desenrolar da trama de Sandra Laing, menina não branca nascida numa família africâner sobre quem versa o enredo do filme, é preciso saber que em 1950 foi decretada uma das leis mais conhecidas do regime do apartheid; ela instituía um registro populacional que carimbava a pessoa com a sua cor desde que nascia. Isso determinava os lugares por onde ela andaria, a escola que frequentaria e quem estaria debaixo de um mesmo teto. Era ilegal ter uma relação interracial. Os atos forma como foram chamadas as leis racialistas - removeram $e$ restringiram os direitos dos "não brancos" ${ }^{3}$ em cada esfera da vida possível (Beinart \& Dubow, 1995:3).

1 Como nos diz o seu título, era um registro populacional que classificava a pessoa nascida em uma das quatro raças designadas pelo governo, quais sejam: branco, coloured, Bantu (negro africano) e outros (Monteiro, 2010).

2 Do original: "Apartheid (Afrikaans for apart-ness) was a system of racial segregation legally enforced by ruling white minority in South Africa from 1948 to 1994. The Population Registration Act (1950) classified all citizens by racial group. People of different races were forbidden to enter the same shop, attend the same school or live under the same roof" (tradução nossa).

3 O regime do apartheid se caracterizava como um sistema de supremacia racial. Legalmente as pessoas eram divididas em raças e à população branca eram designados os privilégios do grupo que ocupava o poder. Portanto, uso aqui o termo não-branco para designar os outros grupos sul-africanos (abarcando negros, coloured, indianos e asiáticos) que possuíram seus direitos negados ao longo do governo do Partido Nacional. 
A palavra apartheid define o caráter do sistema. $\mathrm{O}$ termo escolhido vem do afrikaans, língua falada pelos africâneres (ou bôeres) - minoria descendente de holandeses nascida no que denominam de Afrika. ${ }^{4} \mathrm{O}$ idioma consiste em uma mistura de holandês e diversos outros idiomas, muitos deles falados pelos povos locais. Segundo Krog, Mpolweni e Ratele (2009), a África do Sul branca deu ao mundo a palavra apartheid, tendo sido o regime por ela denominado declarado, posteriormente, pelas Nações Unidas, crime contra a humanidade: "o Partido Nacional que veio ao poder em 1948 transformou-se em um sistema legal vicioso em que os direitos civis e políticos de um indivíduo eram determinados pela cor da pele" ${ }^{5}$ (2009:40).

Alguns dos aspectos distintos da segregação sul-africana foram o alcance e a extensão das suas leis discriminatórias. Muitos serviços - como educação, saúde, transporte - foram progressivamente sendo restringidos e divididos por uma base racial. Até as relações sexuais e maritais entre as pessoas de diferentes cores foram oficialmente proibidas (Beinart e Dubow, 1995:4). Mais do que um conjunto de legislações restritivas, o sistema era referência a uma complexa ideologia somada a uma série de práticas que visavam legitimar diferenças sociais $e$ desigualdades econômicas em todos os aspectos da vida cotidiana (Beinart e Dubow, 1995:4).

A própria categoria africâner, como a criação da identidade de um povo, foi surgindo através da diferenciação e do afastamento que os colonos passaram a ter com relação aos holandeses que apenas passavam pela região do Cabo em suas rotas de comércio. No tempo da Companhia Holandesa das Índias, esses colonos passaram a receber categorias atributivas, muitas vezes pejorativas, como (i) burger que se referia aos

4 Afrika, em afrikaans, refere-se à parte do continente africano onde mora o povo bôer, sendo, portanto, considerada sua terra natal.

5 No original: "the National Party that came to Power in 1948 turned into a vicious legal system in which an individual's civil and political rights were determined by skin colour”, tradução nossa. 
cidadãos da colônia, posteriormente chamados de (ii) bôer (fazendeiro) ou (iii) trekker (migrante). A partir da segunda metade do século XIX até o século $\mathrm{XX}$, o essencialismo de origem holandesa serviu de base para a construção de uma identidade étnica conscientemente trabalhada, que ganhou nuances nos colonos sul-africanos. Dessa forma, passou a existir uma categoria inclusiva e etnicamente definida, o africâner (Rosa Ribeiro, 1990). A partir do contato conflituoso entre os recém-chegados ingleses e os antigos colonos, acompanhado da tentativa de anglicizar os últimos através de medidas tais como a imposição da língua inglesa e da sua religião, a etnicização virou nacionalismo (Rosa Ribeiro, 1990).

Este artigo busca, portanto, traçar rapidamente o caminho pelo qual a ideologia africâner, apoiada por brancos ingleses, foi ganhando forças no cenário político sul-africano - transformandose de um sistema de segregação para o racismo instituído do apartheid $-e$ suas influências diretas no cotidiano das pessoas $e$ nos elementos cosmológicos que mobilizam o seu dia-a-dia.

\section{***}

Para começar, apresento duas histórias que contam as influências do regime do apartheid no cotidiano, trazendo para o texto os diálogos com as mulheres que me acolheram em suas casas. Tais histórias são fruto das conversas que tive com duas delas ao longo do meu trabalho de campo realizado entre abril $e$ agosto de 2011, na província de KwaZulu-Natal, na África do Sul.

Sonto Mhluli mora na região de Nkunzi, localizada na estrada para a pequena cidade de Dundee, e próxima à pequena cidade de Ladysmith, que, embora não seja grande, é um centro de referência daquela região e de diversas zonas rurais que a rodeiam. Na segunda vez em que estive em sua casa, em junho de 2011, conversamos sobre as diversas remoções pelas quais ela e a sua família haviam passado. O diálogo com ela era sempre entrecortado: nessa língua própria que desenvolvemos - uma 
mistura de gestos, inglês e isiZulu ${ }^{6}$ - às vezes nos entendíamos, outras, não.

Os pais de Sonto nasceram nessa extensa zona rural ao redor de Ladysmith. O pai nasceu em uJonono e a mãe em Indaka. Para explicar algumas das constantes mudanças de sua família, ela usou a expressão: Digdig ("dig" é cavar em inglês): "o ônibus veio, então eles removeram".

Quando seus pais se casaram, foram para a região de Ondini (Normandiem). Foi desse lugar que foram deslocados pela primeira vez com a chegada de ônibus e tratores acompanhados de funcionários do governo e policiais dizendo "agora vocês vão". Seguiram para Danhauser, uma pequena cidade ao norte da região que é rodeada por minas de carvão, para depois se mudarem novamente: "veio este trator, a polícia, o soldado dizendo 'apenas vão agora, peguem suas casas, peguem tudo, apenas vão', esse Digdig, muito grande apartheid, levou a casa”. Após essa segunda remoção, se moveram para Qhudeni segundo gogoSonto ${ }^{7}$, essa é uma cidade, mas é também uma região rural bem no interior de KwaZulu-Natal, a qual ela se referiu como Zululândia - onde foram alojados "na casa de lata" $\left(\right.$ shack $\left.^{8}\right)$, em 1976. A área na região para onde foram removidos

6 Opto aqui por manter a grafia original para me referir à língua Zulu.

7 Optei por manter o tratamento local dado às mulheres mais velhas, às quais nos referimos como mama (alguém da mesma linha geracional da mãe) ou gogo (alguém da mesma linha geracional da pessoa mais velha da família) antes de seus sobrenomes como forma de respeito, respeito ao caminho que trilharam ao longo dos anos. Nesses dois casos, exceções, eu me refiro como mama e gogo antes de seus nomes pessoais. GogoSonto é assim chamada por todos que frequentam a sua movimentada casa, já que é uma importante curandeira da região; já mamaZodwa - cuja história será contada a seguir - foi assim apresentada a mim: com o mama antes do primeiro nome, pela Sthenbile que havia me recebido em sua casa na região de Nkhuto, antes de eu visitar Roosboom.

8 Shack poderia ser traduzido como barraco, mas no contexto sul-africano, quando falo de shacks estou me referindo aos barracos feitos inteiramente - teto e paredes - com ferro ondulado (conjugated iron), com o seu uso muito comum também nos telhados das casas das zonas rurais e periferias urbanas, assim como para os banheiros, construídos fora das casas. É ainda usual o uso de grandes pedras em cima deles para que um vento forte não carregue o teto da casa. 
se chama Incandla e foi transformada em uma homeland (nas palavras de gogoSonto: terra de chefe) próxima à cidade, onde estão "até agora". Digo que foi transformada, porque, segundo o relato, o chefe $e^{9}$ chegou depois que as pessoas já tinham sido lá reassentadas e decretou que a terra então era dele: "muito, muito apartheid este chefe".

A mãe de gogoSonto visitava Gauteg para curar as pessoas. ${ }^{10}$ Essa é a província do país onde estão situadas duas de suas capitais, Pretoria e Johanesburgo, sendo a primeira executiva $e$ a segunda econômica. Foi em uma dessas visitas que Sonto nasceu e acabou por morar na província ao longo dos seus primeiros oito anos de vida quando a mãe resolveu voltar para a casa, em Icandla. Reclamando bastante sobre o chefe do lugar, ela falou das desventuras de terem sido removidos para lugares onde não conheciam ninguém.

Durante essas remoções e reassentamentos do governo do apartheid, pessoas de diversos lugares foram colocadas e realocadas juntas por serem classificadas como negras e vistas como uma massa homogênea por parte do governo (Borges, 2009). Entre desconhecidos, as pessoas tinham de dar conta do convívio nos locais (que o governo classificava como reservas bantu) a elas destinados para que pudessem se desenvolver de acordo com os seus "próprios costumes", como requeria a ideologia da segregação.

${ }^{9}$ Em seu processo de deslocamento e homogeneização da população não branca da África do Sul, o governo do apartheid decretou que os africanos institucionalmente denominados de origem bantu deveriam habitar as periferias da cidade, as townships, ou, nas zonas rurais, as áreas designadas bantustões em que se elegia um chefe local, com vínculo e subalternidade ao governo, mas não reconhecido pela população do lugar. Havia ainda aqueles que eram moradores e trabalhadores de fazendas pertencentes a proprietários brancos.

${ }^{10}$ A sua família é composta por pessoas que possuem o dom da cura. A própria Sonto é uma healer doctor como sua mãe e possui uma carteira de identidade desse ofício. 
Zodwa Mbogwa nasceu na região de Roosboom, primeira grande área rural restituída aos antigos moradores (deslocados por agentes do apartheid) pelo programa de reforma agrária do governo democrático no país, situada na estrada que liga Pietermaritzburg a Ladysmith, sendo mais próxima da última. Ao longo do regime do apartheid ela, sua mãe e seu filho foram removidos para a township ${ }^{11}$ de eZakheni que dista o dobro do caminho de Roosboom a Ladysmith. Ela me contou que em 1976 chegaram tratores em seu lote e com uma grande corrente derrubaram a sua casa.

Algumas vezes mamaZodwa me falou sobre o apartheid de formas que não remetiam ao tempo em si do governo segregacionista. Numa noite, estávamos na sala de sua casa acompanhadas pela Fikile - sua prima. Elas então falaram que o meu país era muito bom, pois eu não era como as pessoas brancas de lá: eu me misturava. ${ }^{12}$ Falaram que os brancos sulafricanos quando estão sentados lado a lado com um negro olham com cara feia e não se sentem à vontade: "este país é cheio de apartheid" - importante perceber o presente da afirmação.

Outro dia, havíamos ido à cidade. Na volta, esperávamos pelo taxi ${ }^{13}$ na taxi rank ${ }^{14}$ numa grande fila devido à movimentação de retorno ao campo no fim da tarde. À noite, já na sala de sua casa, mamaZodwa me contou que ainda na cidade, na taxi rank, havia uma mulher incomodada com a minha presença $e$ ao mesmo tempo surpresa comigo ali. Ela, então, reclamou bastante

\footnotetext{
${ }^{11}$ As townships foram criadas pelo governo do apartheid como destino das pessoas não brancas removidas por esse sistema; eram locais longe dos centros das cidades que, por sua vez, passavam a ser ocupados apenas por brancos.

12 Respondi a essa afirmação dizendo que não era bem assim, que no meu país também enfrentávamos um grave problema de racismo que insiste em se dizer velado.

${ }^{13} \mathrm{O}$ transporte público na África do Sul é feito por vans, chamadas de taxi, e é usado majoritariamente pela população não branca.

${ }^{14}$ As taxi rank são como um terminal de ônibus, mas de vans. Cada cidade possui pelo menos um local destinado aos taxis, sendo que algumas possuem mais de uma taxi rank.
} 
da mulher falando que ela não tinha cérebro e que agora as pessoas podem transitar e estar nos mesmos espaços: não estamos mais no apartheid. Aqui a fala, ao contrário do parágrafo anterior, marca o passado.

\section{Legalizando o racismo}

Apartheid machuca, irmã. Ainda

machuca. Às vezes sua memória continua machucando tanto - faz com

que você tenha vontade de matar ${ }^{15}$

(Ratele, 2009:33).

A opressão do apartheid ainda está presente na vida das pessoas. Seus resquícios estão presentes no cotidiano, como nos demonstram as histórias trazidas - seja nas colocações ora referentes ao presente, ora ao passado, seja nas consequências de se ter mudado de lugar por diversas vezes - $e$ a referência ao filme Skin, que conta, a partir da história cotidiana de uma menina, que nasceu com aparência não branca numa família africâner, os meandros do sistema segregacionista em cada detalhe ${ }^{16}$, em que os espaços de convivência diários eram apartados. Dessa forma, quero ressaltar que a intenção aqui não é ficar no mais do mesmo acerca do regime, tão falado e analisado em diversas formas de expressão - seja em livros, filmes ou romances -, e sim pontuar

${ }^{15}$ Do original: "Apartheid hurt, sister. It still does. Sometimes its memory still hurts badly - makes you want to kill", tradução nossa.

${ }^{16}$ Ao ser classificada como coloured, por exemplo, Sandra Laing teve de sair da escola que frequentava, por ser para brancos apenas. A classificação racial foi refeita (de branca, por conta da ascendência, para a aparência coloured) por pressão dos pais de outros alunos e do diretor da escola. A personagem principal casa-se, fugida, com um negro, pois dentre os pares brancos que seus pais the indicavam, não havia a possibilidade de casar. Esses e diversos outros detalhes construíam o seu dia-a-dia como alguém que deveria estar, legalmente, em outro lugar. Uma coloured não poderia morar na mesma casa de brancos ou ocupar a mesma mesa, como deve uma filha. 
que a forma de construção desse regime diz também das relações traçadas até hoje entre as pessoas naquele país.

A ideia de apartheid, antes mesmo do regime, foi posta em circulação pelo africâner Gert Cronjé e depois instituída pelo Partido Nacionalista que ganhou as eleições de 1948. Como exposto acima, a palavra em afrikaans significa separação, separatividade ou caráter do que é separado. O sistema tinha, assim, como argumento a necessidade de apartar as pessoas de diferentes raças para que elas pudessem se desenvolver de acordo com os seus próprios costumes, sem qualquer influência externa. A mistura, pois, era entendida como completamente nociva.

Apesar de minoria mesmo entre as pessoas autorizadas a votar, os africâneres chegaram ao poder pautados num discurso de segurança: o medo em relação aos negros sempre norteou os pensamentos brancos sul-africanos. Mesmo aqueles de origem britânica - teoricamente mais compadecidos politicamente com as injustiças às quais as pessoas de origem africana eram expostas compartilhavam entre si desse medo de uma insurreição negra extremamente violenta. Pois, mesmo que eles se enquadrem na categoria de brancos liberais (white liberals), possuem concepções de lugares constituídas por um medo que as pessoas têm, mas não sabem de onde vem, expresso na grande quantidade de grades, de câmeras de segurança e de muros cada vez mais altos. Medo que reconhece o outro apenas como objeto mítico a ser temido (Crapanzano, 1985). Esse medo acompanhou o regime do apartheid, motivado pelo temor de que se ele acabasse, surgiria uma grande onda negra e violenta. Os brancos viviam assim, de certa forma, como indica Crapanzano, em um tempo de espera, à espera dos bárbaros. ${ }^{17}$

\footnotetext{
${ }^{17}$ Parafraseio aqui o título de um dos livros do famoso escritor sul-africano, John M. Coetze, cuja reflexão versa sobre a espera dos bárbaros que transforma essa própria espera em barbaridade. O livro conta a história de um legista liberal em tempos não falados - à "época do império", mas que fazem sentir meados do
} 
Na coletânea organizada por William Beinart e Saul Dubow, Segragation and Apartheid in twntieth-century South Africa (1995), os editores do livro fazem uma revisão sobre a historiografia do apartheid e da segregação, apresentando-a na introdução. Elucidam também a postura metodológica do livro: o volume enfatiza o papel das ideias e habilidades dos negros sulafricanos de resistir ao controle. Apesar dessa indicação, a análise introdutória é bem teórica e disserta sobre os períodos da segregação e, posteriormente, do apartheid. Pois, apesar dos elementos precursores no período de dominação holandesa (1652-1806), das repúblicas Bôer e das colônias britânicas no século XIX, a ideologia da segregação foi refinada apenas no século XX quando o sistema alcançou sua extensão totalmente (Beinart e Dubow, 1995:1) através da institucionalização do apartheid. Ao seguir processos históricos como a conquista final das chefias (chiefdom) africanas nos 1890 e a consolidação das fronteiras do Estado da África do Sul pelos resultados $e$ consequências da guerra sul-africana de 1899-1902, os autores afirmam que a segregação moderna foi também uma resposta à industrialização iniciada pela descoberta de diamantes e ouro a partir da década de 1860. É feita, pois, uma distinção entre segregação, que emergiu por volta de 1900 a 1948 e apartheid, de 1948 a 1990 (Beinart e Dubow, 1995:3).

Seguindo essa divisão entre segregação e apartheid, os autores afirmam que "o apartheid pretendia ser uma ideologia rigorosa e totalizante de uma forma que a segregação nunca chegou a ser" (Beinart e Dubow, 1995:12). Beinart e Dubow argumentam que a retórica do apartheid tomou de empréstimo das declarações de supremacia branca advindas da era de segregação consideráveis similaridades discursivas, mas que inovou com o apelo central à exclusividade étnica africâner como

período do apartheid - há anos no cargo, que se depara com a investida de uma nova autoridade para descobrir os planos de invasão dos bárbaros na fronteira advindos de rumores de uma suposta rebelião, e através dela Coetzee nos faz pensar quem são os bárbaros da história. Para impedir a invasão, a espera da violência impulsionava caças, capturas e torturas. 
um aspecto distintivo do sistema instalado em meados do século XX (Beinart \& Dubow, 1995:12). Enquanto era contemporânea à época do colonialismo europeu, a segregação na África do Sul não era vista como excepcional. No entanto,

no mundo democratizante do pós-guerra e no tempo da descolonização, o apartheid passou a destacar-se internacionalmente como um sistema imoral de tal forma que a segregação nunca foi considerada (Beinart e Dubow, 1995:12-13).

É, pois, fundamental deixar claro que certamente a segregação e o apartheid prioritariamente serviriam aos interesses dos brancos. No entanto, explicações monocausais como a "herança" africâner ou análises economicistas de que o sistema se movia pelos imperativos da mão-de-obra barata que a segregação abastecia são inadequadas, embora ambas sejam importantes para se analisar aspectos da forma particular que a segregação e a ideologia racial tomaram na África do Sul. Entretanto, para se entender a segregação e o apartheid há de se levar em consideração um leque maior de referências históricas $e$ ideológicas, assim como as premissas cotidianas que ajudaram a manter as noções de diferença racial e privilégios políticos (Beinart e Dubow, 1995:21).

A construção da ideologia africâner foi feita através de mitologias que retomavam o período colonial quando seus ancestrais - chamados de voortrekkers ou trekboer: pecuarista itinerante - deixaram a província do Cabo para se aventurar no interior do país à procura de uma vida que pudesse ser menos pautada pelos novos colonos que chegavam da Inglaterra com ideais intervencionistas diferenciados da administração até então holandesa (Rosa Ribeiro, 1990).

Com a chegada dos ingleses no início do século XIX e seus ideais igualitários que impuseram uma política jurídica de iguais perante a Deus, foram demarcadas as diferenças entre os colonizadores dessas duas origens europeias, forçando os bôeres a adentrarem cada vez mais as terras sul-africanas ao tentarem fugir 
das políticas britânicas. Em 1834 foi decretada a abolição da escravatura em todas as colônias inglesas, o que provocou o GrandTrek (migração em massa/ grande migração de carros de boi de uma parte significativa de bôeres), movimento de sair da Colônia do Cabo, mais ao sul, para mais perto do Transvaal e de Natal (Rosa Ribeiro, 1990). Os participantes dessa grande Trek (migração ou jornada) passaram a ser denominados a partir do século XIX de pioneiros, Voortrekker em afrikaans.

Essa migração foi o ponto de partida de dois mitos africâneres, ocorridos em 1837. O primeiro diz respeito ao episódio de martírio de Piet Retief (Rosa Ribeiro, 1990:29), numa batalha em que os zulus haviam derrotado os bôeres. Esta, por sua vez, foi seguida do segundo encontro entre bôeres e zulus e a famosa batalha de Blood River no dia 9 de dezembro de 1837 (Rosa Ribeiro, 1990), que resultou na derrota de parte do exército zulu do rei Dingane pelos colonos, enquanto expandiam as suas fronteiras para o interior do território. Na reviravolta branca, portanto, zulus foram derrotados mudando a nomeação do Rio Ncome para Blood River: "quando o sangue de três mil guerreiros zulus mortos pintou o rio, tornando-o tinto" (Rosa Ribeiro, 1990:29). Esse dia foi então consagrado como o Dingaan's Day (em relação ao nome do chefe derrotado) e a partir de 1948 tornou-se o Day of Covenant (Dia do Pacto) (Rosa Ribeiro, 1990:29-30). Ou seja, no período sob as leis de segregação, foi nomeado de acordo com a derrota (Dingaan's Day), no período do apartheid, no entanto, o nome foi modificado para o Dia do Pacto.

Líderes africâneres são até hoje nomes de cidades e ruas pela África do Sul. Como é o caso de Pietermaritzburg ${ }^{18}$, hoje sede de diversas ONGs que lutam pela reparação dos direitos renegados aos negros durante anos das leis segregacionistas. Pretoria, atual capital executiva do país, também leva o nome de um líder africâner: "Pretorius, líder do comando que derrotou os zulus, teria seu nome imortalizado no da futura capital da República Sul-

${ }^{18} \mathrm{O}$ nome dessa cidade vem da junção do nome de dois líderes Voortrekkers: Piet Retief - nome de uma das principais ruas da cidade - e Gert Maritz. 
Africana do Transvaal" (Rosa Ribeiro, 1990:34). Essas mesmas cidades têm outros nomes em isiZulu. Pretoria é ePitoli; Pietermaritzburg, muitas vezes chamada apenas de Maritzburg, é eMgungundlovu; Johanesburgo, conhecida como Jo'burg, é eGoli. Além do próprio nome do país - iNingizimu Afrika e de outras cidades como Durban, Ladysmith e Cape Town: eThekwini, eMnambithi e eKapa, respectivamente.

A historiografia africâner foi então se fazendo através desses mitos, tentando sempre afirmar a sua legitimidade enquanto povo, tais como:

os brancos e os negros (Nguni, Sotho, Venda e Tsonga) teriam chegado ao mesmo tempo na África do Sul; os negros teriam migrado até encontrar-se com os brancos na fronteira oriental do século XVIII; os Voortrekkers teriam penetrado em terras vazias e sem dono (Rosa Ribeiro, 1990:47).

Essas versões, "presentes também nos livros escolares" (Rosa Ribeiro, 1990:47), eram facilmente colocadas em xeque e derrubadas diante de evidências históricas e arqueológicas acerca da presença dos negros no continente. Exceto a parte da província do cabo habitada também pelos Khoikhoi e San, de pele mais clara, mas não branca. De fundo, esse mito justificava a sua dominação, pois afirmava que os bôeres "encontraram a África do Sul vazia de qualquer ocupação humana, o que lhes havia conferido uma espécie de autoctonia exclusiva" (M'Bokolo, 2004:541).

Somada a essa historiografia usada para legitimar a identidade africâner enquanto autóctone da Afrika, a teoria antropológica do relativismo cultural, à época em desenvolvimento, também foi "adotado pelos ideólogos da segregação que proclamaram a necessidade de preservação das distintas identidades pelas diferentes culturas $e$ a necessidade de manter a coerência interna das sociedades africanas" (Beinart e Dubow, 1995:4). 
Aos poucos, assim, as leis iam consolidando a identidade africâner em seus vários aspectos, desde a oficialização do afrikaans, em 1925, forçando uma paridade com o inglês num objetivo que "visava um enobrecimento da língua como tema central da história africâner" (Rosa Ribeiro, 1990); como na fundação, em 1918, da Afrikaner Broederbond - Liga Africâner dos Irmãos (Fraternidade Africânder), que a partir de 1922 tornouse uma organização secreta que tinha como intenção promover a africaneridade nas áreas cultural, política e econômica. Adam Kuper (2000:159) nos informa que "todos os professores de etnologia nas universidades africânderes eram membros do Broederbond, a sociedade secreta que estava no coração do establishment africânder". A Igreja Reformada Holandesa foi eleita a Igreja Nacional do povo africâner, delimitando sua diferença em relação aos ingleses, anglicanos em sua maioria $e$, reforçando os laços cristãos do regime. Foi, portanto, na costura de todos esses aspectos que se consolidou a noção de pertencer a um povo (Rosa Ribeiro, 1990). Sua ideologia foi a união da raça, língua e religião para a formação de um Estado Nacional segregado, cuja marca era o texto legal. Em 1924, o Partido Nacionalista assumia o poder pela primeira vez e nele se manteria até 1933, para depois reassumir e finalmente instituir o apartheid em 1948.

Muitos acadêmicos também argumentam que a ideologia de segregação não está restrita à parcela africâner da população branca da África do Sul - como já explicitado de alguma maneira neste texto. A segregação em Natal, por exemplo e como dito acima, teve início nas colônias britânicas que oficializavam o governo indireto (Beinart e Dubow, 1995:4), característica da colonização inglesa. Martin Legassick argumenta que as relações raciais eram mais fluídas nos séculos XVIII e XIX, e que os formuladores de políticas falantes de inglês desempenharam um papel fundamental na construção da ideologia segregacionista (apud Beinart e Dubow, 1995:7), ilustrado no documento da South African Native Affairs Comission (1903-5) produzido por esse grupo - britânicos e falantes de inglês - "que de diversas formas 
sistematizava políticas nativas de segregação para o futuro" (Beinart e Dubow, 1995:7).

Através desse sistema, portanto, o uso da lei tornou-se arma poderosa para perpetrar abusos e anular direitos, como a cidadania. Através de uma violência no legalismo, mantinha-se um referencial comunitário para a relação "dos outros, negros tribais, definidos como toda pessoa que é geralmente aceita como membro de uma raça aborígene ou de uma tribo da África" (Rosa Ribeiro, 1990) para reforçar o argumento de não intervenção numa forma diversa de se viver: eles, negros e comunitários, teriam reservas destinadas a morarem de acordo com seus valores como vimos na narração de gogoSonto -, enquanto os brancos e civilizados, desenvolveriam sua terra baseados em ideais cristãos de trabalho. Dessa forma, desenvolveu-se um modo de governar autoritário, que de fundo se baseava no ideal judiciário branco e democrático, mas que apenas servia para legitimar um sistema que formalizava

seus atos sempre por meio de leis. O que ocorreu foi
um processo ordenado de legalização e
institucionalização de práticas segregacionistas,
tornando coercitivo o seu cumprimento. Estas leis
revelam, pois, o conteúdo do regime. Durante mais de
meio século, elas serviram de sustentação e respalda
às ações governamentais (Monteiro, 2010:16).

A legislação desse regime, incluindo o período pré-apartheid, instaurou uma forma discriminatória na lei que subtraiu dos negros o direito de possuir uma terra ou até mesmo de possuir um local de morada onde estivessem também seus ancestrais, pois além de negar à propriedade aos não brancos, esse sistema removeu massivamente as pessoas de suas casas e terras, ora as colocando em reservas delimitadas pelo governo, ora em subúrbios citadinos tão cheios de desconhecidos como os primeiros.

É importante, entretanto, frisar que o apartheid 
não era apenas um sistema legal, se fazia também através dos costumes (como no ambiente de trabalho, onde somavam-se às colour bars instituídas as já sempre ocupadas posições de supervisão pelos brancos), das convenções (como igrejas separadas desde sempre), assim como o trabalho migratório que assegurava a dificuldade de movimentação dependia não apenas da lei de passe, posteriormente decretada, como de uma série de premissas sócio-culturais (Beinart e Dubow, 1995:5).

Seguindo a linha do que aqui se pretende pensar (com um olhar voltado para o dia-a-dia presente nas estórias contadas $e$ escutadas através da convivência), inspirada também pelas questões levantadas por diversos autores - como Njabulo Ndebele ${ }^{19}$ que nos fala da importância do ordinário na literatura africana, que podemos expandir para outras formas de se pensar e escrever -, é importante atentar em como "o imaginário e as ideias cotidianas sobre poluição e contágio (tão clássica na literatura antropológica) podem se entrelaçar a teorias médicas formais para produzir políticas de segregação" (Beinart e Dubow, 1995:7). Foi o caso, por exemplo, do segregacionismo urbano, em

${ }^{19}$ Njabulo Ndebele (2006) fala sobre a escrita literária de negros sul-africanos a partir da análise de obras que se enquadram em um método de espetacularização política a que ele se opõe; e traz histórias que para ele atentam para os detalhes cotidianos, sem deixar de serem políticas. O primeiro método parece ter um apreço por um certo tipo de se fazer política que impõe uma literatura do espetáculo transformando a escrita em símbolos, com significados instantâneos: ver é significar (Ndebele, 2006:38). Possui, assim, uma forma de narrar que confirma sem a necessidade de reflexão. Explicitando nesse argumento seu incômodo com a hegemonia do espetáculo como discurso político único na literatura negra sul-africana, que se impõe como o modelo possível, o autor sugere então que se quebre a barreira da demonstração e da obviedade para revelar novas possibilidades de se entender e de agir (Ndebele, 2006:46). O ordinário é aqui definido em oposição ao espetacular. "Racional e não-racional constituem a mesma esfera da realidade" (Ndebele, 2006:51). Ao final do texto, o autor nos mostra que as últimas três histórias analisadas, no âmbito do ordinário, nos lembram que a vida cotidiana das pessoas deveria ser o foco do interesse político, pois elas constituem a principal parte da luta, "já que a luta envolve pessoas e não abstrações" (Ndebele, 2006:52). 
1901, que se fez em resposta à deflagração da peste bubônica na Cidade do Cabo, quando milhares de africanos foram removidos do centro da cidade com o argumento de que isso facilitaria o controle da praga, "ação que segundo Maynard Swanson deve ser situada dentro do mundo do Império Britânico na virada do século, mais do que como parte de um legado afrikâner ou sulafricano" (apud Beinart e Dubow, 1995:6-7).

A segregação surgia então como uma ideologia guardachuva que era capaz de servir a diversos grupos de interesse branco. Sua natureza flexível favorecia (i) aos fazendeiros brancos um pronto abastecimento de trabalho, (ii) às minas a segurança do sistema de trabalho migratório ao qual haviam se tornado dependentes e (iii) aos trabalhadores brancos a proteção no mercado de trabalho (Beinart $e$ Dubow, 1995:10-11).

Olhar para o cotidiano nos permite ver as movimentações feitas do outro lado, do lado que não escrevia as leis, mas as vivenciavam na pele. Exemplos como os

dos anos 1920s quando movimentos massivos emergiram nas zonas rurais sul-africanas ao desafiaram as regras brancas alinhando formas urbanas de protesto com expressões rurais mais tradicionais de resistências" (Beinart $e$ Dubow, 1995:9)

nos mostram a mobilização contra o regime, mesmo no período pré-apartheid. Para "se capturar analiticamente a longevidade" ainda caminhando aqui com as palavras de Beinart e Dubow - da dominação racial na África do Sul, é preciso se levar em conta "o balanço de poder na sociedade sul-africana, a natureza das respostas africanas e a relevância da etnicidade entre negros como também entre brancos" (Beinart e Dubow, 1995:21-22). Já que é "precisamente este detalhe cotidiano que é investido com a história da deslocação, perda, pobreza e subjugação" (Krog, Mpolweni e Ratele, 2009:183). Esse dia-a-dia, por sua vez, foi 
composto pela noção instituída de que a propriedade no país era branca - a partir da Lei de Terras, de $1913 .{ }^{20}$ Esse é um "detalhe" fundamental.

\section{Pessoas deslocadas: famílias compostas por senhoras e crianças}

No passado eles paralisaram o poder do povo. Eles lhes tiraram suas terras. ${ }^{21}$ (Mnyah Dlamini, interlocutor de Gotlib, 2010:83)

Ao contrário do que a maioria branca esperava, o momento eufórico das eleições em 1994 levou a uma catártica baixa significativa nos níveis de violência (Beinart e Dubow, 1995:21). Apesar de os africanos terem votado com uma maioria esmagadora num partido cujo discurso era de que negros e o país se reunissem em um comum nacionalismo não racial (Beinart $e$ Dubow, 1995:21), "a votação seguiu as linhas das cores em um grau significativo e o Inkhata ( $10 \%$ dos votos) sobreviveu como uma força especificamente zulu" (Beinart e Dubow, 1995:21). A região de Western Cape angariou ainda ao Partido Nacional (20\% dos votos) apoio não apenas dos brancos, como de uma parcela dos coloured que garantiu a vitória nacionalista na região. No período democrático, então, nove regiões substituíram as 4 províncias e 10 homelands do apartheid.

\footnotetext{
${ }^{20}$ O Native Land Act, de 1913, regulamentava sobre a propriedade de terra no país, destinando apenas $13 \%$ delas aos negros e os proibindo de adquirir qualquer propriedade a partir de sua implementação. Tal lei trazia provisões de outro decreto, ainda do período colonial: no fim do século XIX foi promulgada a "primeira lei de cunho racista, o Glen Grey Act (1894). Esse ato proibiu os africanos de comprar e titularizar terras que estivessem fora do montante de 7\% reservado à ocupação da população negra" (Monteiro, 2010:17).

${ }^{21}$ Do original: "In the past they paralyse the power of the people. They took off their land", tradução nossa.
} 
Como já falado anteriormente, apesar de findo o regime, a segregação persiste cotidianamente no país:

Como "ouvimos" um ao outro em um país em que o passado ainda é tão presente entre a gente? Quanto do que ouvimos podemos traduzir em achar os caminhos para se viver juntos? Como podemos superar um passado dividido de tal forma que o "O Outro" se torne "nós"?22 (Krog, Mpolweni e Ratele, 2009:42-43).

Pensando nessa presença de um passado no cotidiano, gostaria de trazer a centralidade da terra para entendermos o contexto sul-africano atual. Essa centralidade entra em choque com outras formas dominantes de se pensar a terra que respingam nas faltas de comunicação entre as pessoas de diferentes cores no país.

Os trabalhos de Aina Azevedo (2013), Paula Monteiro (2010), Joyce Gotlib (2010), Antonádia Borges (2008, 2009) e Marcelo Rosa (2008, 2009, 2011), Deborah James (2007), Cherryl Walker (2003, 2005) e Ntsebeze e Hall (2007) nos ajudam nessa questão, que é, por sua vez, relacionada à ancestralidade e às influências das leis segregacionistas numa forma de se estar na terra que põe em xeque a nossa própria noção de propriedade. Implica, pois, relações ancestrais, relações familiares e, sobretudo, sentimento de reparação das injustiças que remetem ao período anterior (Rosa, 2009). A relação entre a ancestralidade e a terra "terra é sinônimo de ancestralidade" (Azevedo, 2013:63) -, em seu lugar, está vinculada aos rituais chamados de umsebenzi (ritual para os ancestrais), em isiZulu, realizados massivamente ao longo dos meses de junho e julho, os quais pude acompanhar.

Os rituais para os ancestrais feitos hoje em dia estão, muitas vezes, relacionados às pendências deixadas pelo passado de remoção em que se perdiam parentes sem os enterrar

\footnotetext{
22 Do original: "How do we 'hear' one another in a country where the past is still so present among us? How much of what we hear can we translate into finding ways of living together? How do we overcome a divided past in such a way that 'The Other' becomes 'us'?”, tradução nossa.
} 
devidamente e sem fazer os rituais após um ano da morte. Tais pendências são relacionadas àquelas pessoas da família de quem nem se tinham mais notícias. Os ritos são feitos quando algo na vida das pessoas não vai bem. Procura-se o especialista, para dialogar com os ancestrais, que indicará o caminho acerca do que deve ser feito. A partir daí, toda uma estrutura é montada para a realização do ritual aos ancestrais para que a pendência seja resolvida. Esta consiste em adquirir os animais sacrificados (cabras para se comunicar com os ancestrais e vacas para alimentar as pessoas), os alimentos oferecidos ao longo da cerimônia, o aluguel de tenda e de cadeiras. Para tamanho custo, muitas mulheres se reúnem em grupos de apoio, Women's Club, e, quando solicitados, cada uma das participantes fornece uma quantia específica para a solicitante. Há ainda os grupos mistos, conhecidos como Burial Societies, cujos fins são os mesmos. Ao longo do meu trabalho de campo, pude acompanhar diversas reuniões desses grupos e também alguns umsebenzi.

A propriedade, assim, ainda aparece como símbolo da segregação, devido à proibição legal de propriedade $e$ despossessão (privação da posse) ao longo dos anos, mesmo daqueles que já eram proprietários. Surge assim na legislação pósapartheid de reforma agrária a ideia de um "instituto da posse [que] aparece como forma de se opor às disposições legais" (Monteiro, 2010), "relativizando o direito de propriedade que tão bem serviu ao apartheid, de forma que ter a posse, ainda que não o título de propriedade, significa estar seguramente na terra que, por tantos anos, lhe foi denegada" (Monteiro, 2010:99). Essa posse de terra é então relacionada às várias formas de se pertencer à ela e menos a se ter um pedaço de papel, que embora extremamente importante para lhes garantir a propriedade, já foi por anos deslegitimado.

Para tratar dessa questão, quero rapidamente tecer algumas palavras sobre um programa de televisão sul-africano que explicita as consequências das deslocações promovidas pelo governo segregacionista. Com a negação do direito à posse, os trabalhos distantes $e$ as constantes remoções, muitas pessoas foram 
separadas de familiares que se inseriram nesse percurso por um lugar legal para morar somado às buscas em achar alguma forma de sustento, já que as ofertas de empregos para as pessoas não brancas estavam majoritariamente nas cidades, onde eles podiam circular apenas com permissão e à trabalho, nas indústrias ou nas minas.

O título do programa televisivo exibido às quartas-feiras à noite é Kumbula'e'khaya, em isiZulu. Foi na casa da mamaZodwa que tive o primeiro contato com esse programa enquanto ela me contava algumas coisas sobre a sua vida, dentre elas, sobre a remoção em 1976. Contava ainda que não se dava muito bem com as poucas pessoas da sua família materna, nem com as duas irmãs ainda vivas. Preocupava-se, então, com quem iriam ficar as coisas que tinha dentro da sua casa quando ela morresse, já que seu único filho havia falecido. Mas, em seguida, falou que já tinha uma solução para o seu problema: escreveria para o Kumbula'e'khaya para achar a sua família por parte de pai, que ela nunca conheceu, já que quando ela nasceu, ele saiu de Roosboom em direção à Durban para procurar emprego e nunca mais voltou. Além disso, ela afirmou naquele momento que gostava muito do programa. Exibido pelo canal SABC 1 (South Africa Broadcasting), o programa possui uma hora de duração, o que é incomum aos programas cotidianos que costumam durar meia hora, incluindo as novelas. Além disso, começa depois da programação diária, às $21 \mathrm{~h}$, sendo o programa que vai até mais tarde assistido pelas pessoas nas zonas rurais que conheci e que possuíam energia elétrica em suas casas.

Foi, no entanto, na casa de Thobekile Radebe - ativista por muitos anos do Landless People Moviment (Rosa, 2008, 2009, 2011; Borges 2008, 2009) - que pude prestar mais atenção ao programa que passava na televisão. O programa é patrocinado pelos correios com abertura e slogan de cartas escritas à mão voando, levadas ao vento. É um programa muito bonito. Essas cartas fazem referência às próprias palavras das pessoas que escrevem à produção contando sua história e pedindo ajuda para que possam encontrar parentes perdidos, não vistos há muito 
tempo pela família, ou o inverso, uma pessoa procurando achar a família com a qual perdeu o contato por anos. Algumas dessas cartas que voam, portanto, são transformadas em histórias de pessoas que se reencontram ou que não são achadas, filmadas $e$ exibidas na televisão.

$\mathrm{O}$ nome do programa não foi traduzido acima propositadamente. Demorei um tempo para chegar a uma definição. Primeiro aprendi que Khumbula é miss em inglês, que poderíamos traduzir como sentir falta, e já sabia que Khaya era casa. Pedi, então, tanto à mamaZodwa, como à Thobekile para traduzirem o título para mim [a tradução era sempre meio complicada, quando pedia o significado de algumas palavras, diversas pessoas hesitavam antes de me responder, mesmo em relação aos nomes - comuns cotidianamente e óbvios em isiZulu, mas não em inglês]. ${ }^{23}$

Cada uma delas, no entanto, deu um toque particular à definição, embora não divergentes. MamaZodwa falou que era algo como "você precisa lembrar de casa, quando sente a sua falta", sendo que ela já havia me traduzido diversas expressões em que começava a tradução com "você deve/precisa" ("you must", em inglês). Isso parece ter a ver com a sua forma de encarar o mundo e de falar inglês, que aprendeu sozinha. Já Thobekile me disse que era "lembre-se de sua família em casa".

Casa, assim, tem um sentido muito peculiar ali, de pertencimento, como a relação de posse com a terra. Em inglês, as pessoas nos falavam sobre a home, casa onde estão seus ancestrais, diferente mesmo da casa onde podem morar, house, mas onde não estão enterradas as pessoas da sua família. Procurar a casa, portanto, no sentido de home, é de extrema importância num contexto onde as pessoas foram diversas vezes

\footnotetext{
23 "Traduzir uma língua africana não é uma tarefa fácil, já que muitas das palavras e expressões têm tanto um significado literal, quanto figurativo, que são simultaneamente presentes" [Do original "To translate from an African language is no easy task, as many of the words and expressions have both a literal and figurative meaning that are simultaneously present", tradução nossa] (Krog, Mpolweni e Ratele, 2009:74).
} 
removidas, proibidas de se locomover e impossibilitadas de visitar seus túmulos ou de ter seus ancestrais lhes acompanhando. As remoções e as necessidades de se mudar implicaram no trânsito entre corpos, ancestrais e obrigações rituais para com eles, amplamente influenciadas e por vezes impedidas pela legislação que ia a cada ano diminuindo a possibilidade de se locomover dos não brancos.

Além da noção de pertencimento, é preciso entender o papel desenvolvido pelas mulheres na constituição dessa casa. A literatura clássica diz que o casamento faz da mulher a mãe da casa: "um estado composto pelas suas crianças e outros dependentes juntamente com os campos, animais, bens $e$ moradas que lhes dão suporte - dentro do homestead agnático de seu marido" 24 (Gluckman 1950; Comaroff and Roberts 1981:47-53; Oberler 1994 apud White 2011:108). Apenas sendo maridos para as mães da casa - das mães que criam crianças nomeadas a eles - os homens podem assegurar seu caminho da paternidade para a ancestralidade (White, 2011:108). Pois é através do homestead do seu neto, e não do seu filho, que o homem se torna não apenas "um pai respeitado, mas também um espírito ancestral rememorado. O seu neto é a incorporação da sua prosperidade" (White, 2001:466).

Apesar da ancestralidade e do nome serem passados pela patrilinearidade, cabe às mulheres mais velhas moradoras das regiões rurais, hoje, tornarem possíveis os necessários rituais para os ancestrais. Além dessa responsabilidade, como dito acima, são elas que garantem aos homens se tornarem pais e, portanto ancestrais: "quando mulheres fazem pessoas" (White, 2011:109). Cuidam dos umsebenzi, garantem a comida a ser servida e os auxílios para todos os materiais necessários. São elas também que cuidam das crianças, quando os pais, homens e mulheres, saem do campo em busca de trabalho, como nas famílias que encontrei.

\footnotetext{
${ }^{24}$ Do original: "an estate composed of her children and her other dependents along with the fields, animals, goods and dwellings that supported them - inside her husband's agnatic homestead", tradução nossa.
} 
Nesse cotidiano, povoam os dias programas de televisão pautados por temáticas que mobilizam o dia-a-dia. Para entender a possibilidade de se criar e se assistir a um programa de televisão para o qual milhares de pessoas escrevem - com cartas voando ao vento - procurando encontrar aqueles que foram perdendo ao longo do caminho de diversas moradas, é preciso saber o que motivou a locomoção e as formas de continuamente manter os negros em movimento, fossem migrando, fossem sendo deslocados: para não criar raiz. $\mathrm{Na}$ temporalidade da ancestralidade, no entanto, o que ficou (desenraizado), retorna ao presente em formas de desavenças pelas quais as pessoas estão passando e que precisam ser resolvidas através dos umsebenzi, daí a necessidade de se encontrar as pessoas perdidas ao longo do caminho.

As histórias aqui evocadas nos mostram os percalços cotidianos que as pessoas enfrentaram, e enfrentam, diante de um governo que lhes mudava compulsoriamente de lugar - sempre declarado impositivamente como brancos - para dar conta daquelas coisas que para eles eram também muito poderosas. $\mathrm{O}$ que procurei explicitar é que a violência perpetrada pelo apartheid não atingiu apenas os vivos. No âmbito do ordinário, o peso do governo que restringia todo e qualquer direito foi também sentido naquilo que é fundamental: a presença dos ancestrais $e$ a importância de se estar bem com eles. É, pois, preciso agora, num período democrático, construir casas onde as memórias não sejam destruídas ${ }^{25}$ a partir dos direitos restituídos e que os ancestrais não precisem acompanhar um movimento imposto $e$

\footnotetext{
${ }^{25}$ Faço aqui referência à citação feita pelos autores Krog, Mpolweni e Ratele do livro The Cry of Winnie Mandela, de Ndebele: "eu sonho com que as minhas crianças possam construir casas do tipo que me escaparam; casas que não poderão nunca serem demolidas pelo Estado em ordem de transformar as memórias impossiveis" [Do original, "I dream that my chlidren may build homes of the kind that eluded me; homes that can never be demolished by the state in order to make memories impossible", tradução nossa] (Ndebele apud Krog, Mpolweni e Ratele, 2009:185). A casa não é só a home, mas é também o lugar de construção de memórias.
} 
frequente. É preciso, assim, retomar casas, no sentido de home, onde se possa criar raiz - terras em que os mortos tenham posse do chão (Couto, 2003).

\section{Referências bibliográficas}

AzEVEDO, Aina. Três lugares para viver e um para morrer - O sentido das casas na África do Sul. Projeto de qualificação de doutorado, Antropologia Social, Universidade de Brasília (UnB), 2009.

. Conquistas Cosmológicas: pessoa, casa e casamento entre os Khubeka de KwaZulu-Natal e Guateng. Tese de doutorado, Antropologia Social, Universidade de Brasília (UnB), 2013.

BEINART, William; DuBOw, Saul (orgs.). Segregation and Apartheid in twentieth-century South Africa. Londres, Routledge, 1995.

BORGES, Antonádia. Bruxaria como (pre)conceito: contrastes etnográficos e os limites da linguagem em antropologia. Trabalho apresentado na $32^{a}$ ANPOCS, em Caxambu - MG, no Grupo de Trabalho "Entre Fronteiras e Disciplinas: estudos sobre África e Caribe", 2008a.

. Tsotsi and Yesterday: an anthropological appraisal. Vibrant Virtual Brazilian Anthropology, vol.5, no 2, Brasília, 2008b, pp.246267 [http://www.vibrant.org.br/issues/v5n2/ - acesso em: 23 mar. 2015].

. Explorando a noção de etnografia popular: comparações $e$ transformações a partir dos casos das cidades-satélites brasileiras $e$ das townships sul-africanas. Cuadernos de Antropología Social n ${ }^{\circ} 29$, Buenos Aires, 2009, pp.23-42.

COETzEE, John. À espera dos bárbaros. São Paulo, Editora Best Seller, 1980.

Couto, Mia. Um rio chamado tempo, uma casa chamada terra. São Paulo, Companhia das Letras, 2003.

GOTLIB, Joyce. "Getting people back to the land": a interdependência entre governo e ONGs na produção de beneficiários por terra na província de KwaZulu-Natal, África do Sul. Dissertação de mestrado, Sociologia e Direito, Universidade Federal Fluminense, 2010. 
JAMES, Deborah. Gaining Ground? Rights and property in South African land reform. Johannesbourg, Wits, 2007.

KrOG, Antjie; MrOlwenI, Nosisi; KoPANO, Ratele. There was this Goat. Scottsville, University of KwaZulu-Natal Press, 2009.

KuPER, Adam. The "House" and Zulu Political Structure in the Nineteenth Century. The Journal of African History, vol. 34, $\mathrm{n}^{\circ} 3$, Cambridge University Press, 1993, pp.469-487.

- Entrevista, Colônias, Metrópoles: um antropólogo e sua antropologia. Mana 6(1), Rio de Janeiro, 2000, pp.157-173.

M'BOKOLO, Elikia. As práticas do apartheid. In: FeRRO, Marc (Org.). O livro negro do colonialismo. Rio de Janeiro, Ediouro, 2004, pp.540560.

MELLO, Fabrício. Pluralidade e mediação: ONGs e indivíduos na reforma agrária sul-africana. Monografia de graduação, Ciências Sociais, Universidade Federal Fluminense, 2009.

MonTEIRO, Paula. Desafiando o direito de propriedade: $\mathrm{O}$ embate entre diferentes concepções de direito à terra no contexto de reforma agrária sul-africana. Monografia de graduação, Ciências Sociais, Universidade Federal Fluminense, 2010.

NDEBELE, Njabulo S. The rediscovery of the ordinary: some new writings in South Africa. In: Rediscovery of the Ordinary. Essays on south African literature and culture. Durban, University of KwaZuluNatal Press, 2006, pp.31-54.

NTSEBEZA, Lungisile; Hall, Ruth. The Land Question in South Africa: the challenge of transformation and redistribution. Cape Town, HRSC Press, 2007.

RosA, Marcelo. Estado e ações coletivas na África do Sul e no Brasil: por uma sociologia contemporânea dos países não exemplares. Sociologias ano 10, n 20, jul./dez, Porto Alegre, 2008, pp.292-318.

- Espectros de Mamdani: desafios de uma sociologia da vida política rural na África do Sul contemporânea. Estudos de Sociologia, vol. 15, n² 2, Recife, 2009, pp.69-91. 
. Mas eu fui uma estrela do futebol! As incoerências sociológicas e as controvérsias sociais de um militante sem-terra sul-africano. Mana vol.17, n² 2, Rio de Janeiro, 2011, pp.365-394.

RIBEIRO, Rosa; FerREIRA, Luiz Fernando da. Apartheid: o reino de Deus na terra. Dissertação de mestrado, Antropologia Social, Universidade de Brasília (UnB), 1990.

VALE, Maíra Cavalcanti. Prosa que tece a vida, estórias de mulheres em KwaZulu-Natal, África do Sul. Dissertação de mestrado Antropologia Social, Universidade Estadual de Campinas (Unicamp), 2013.

WHITE, Hylton. Beastly whiteness: Animal kinds and the social imagination in South Africa. Anthropology Southern Africa 34(3\&4), 2011, pp.104-113. 